\title{
PENGELOLAAN KAWASAN \\ LAHAN BASAH SEBAGAI HABITAT BURUNG MIGRAN DI TAMAN NASIONAL WASUR
}

(Wet Land Area Management for Habitat of Migrant Bird in Wasur National Park)

\author{
Damianus V.S. Woghomugu ${ }^{1}$ dan Hermanus Warmetan ${ }^{1 凶}$ \\ Jurusan Kehutanan, Fakultas Kehutanan Universitas Papua Manokwari, Papua Barat, \\ 98314. Tlp/Fax: +62986211065. \\ 『Penulis Korespondensi: Email: h_warmetan@yahoo.co.id \\ Diterima: 10 Okt 2017| Disetujui: 18 Nov 2017
}

\begin{abstract}
Abstrak
Penelitian ini bertujuan untuk memberikan gambaran peran penting kawasan hutan lahan basah dan deskripsi pengelolaan kawasan lahan basah sebagai habitat burung migran di kawasan Taaman Nasional Wasur. Metode yang digunakan yakni deskriptif dengan menggunakan kumpulan data-set dan kompilasi referensi-referensi terkait sebagai komparasi dalam penataan dan pengelolaan TNW sebagai kawasan alternatif migrasi. Hasil penelitian menunjukkan bahwa kawasan lahan basah TNW memiliki keunikan dengan ciri iklim serta pola cuaca yang tidak tetap sepanjang tahun. Kekhasan keanekaragaman di kawasan TNW dipengaruhi oleh tipe hutan, daerah keterisolasian spesies, daya segmentasi kawasan, sehingga membentuk satuan habitat unik. Tercatat tipe ekosistem dominan masih didominasi ekosistem basah, dengan tipe daerah rawa. Jenis kelompok vegetasi utama yang dijumpai yaitu dari kelompok Melaluca dengan jenis: Melaleuca spp., Lophostemon lactifluus, Xanthostemon sp., Acacia leptocarpa, Salsar, Asterom. Selain itu jenis vegetasi hutan savana yang dominan di temukan yakni: Lophostemon lactifluus, Banksia dentata, Asteromyrtus symphiocarpa. Keterlibatan masyarakat dalam upaya pengelolaan kawasan telah dilakukan dan memberikan manfaat nyata. Tercatat setiap tahun terjadi mingrasi burung sebagai jalur alternatif persinggahan terutama antar benua ketika perubahan musim tahunan terjadi.
\end{abstract}

Kata kunci: Lahan basah, taman nasional wasur, burung miggran, hutan rawa.

\begin{abstract}
The objective of thi study was to describe an overall importance of wet land forest area and its overview of wet land management that functions as a temporary migrant bird habitat in the area of Wasur National Park. Method used was descriptive by way of collecting dataset and compilling related refereces as comparison in desaining and managing Wasur National Park as an alternative migration area. The result pointed out that the wet land area of Wasur National Park possessed a unique of climatic and weather pattern which was quite unpredictable over the year. In addition, the unique of biodiversity rate in the area was also spurred by forest type, isolated species area, the ability of segmented area, these then shape a distict habitat. It has been noticed that the dominant ecosystem type in the area was wet ecosystem which was identical with swampy areas. The majority group of vegetation found was Melaleuca such as: Melaleuca spp., Lophostemon lactifluus, Xanthostemon sp., Acacia
\end{abstract}

111

@ Asosiasi Peneliti Biodiversitas Papuasia - Fakultas Kehutanan UNIPA 
leptocarpa, Salsar, Asterom. Besides, savannah vegetation that appeared such as: Lophostemon lactifluus, Banksia dentata, Asteromyrtus symphiocarpa. Traditional forest community has been engaged in conjunction with preservation activities. Migration of bird has been occurring every year as an alternative path way to tempory stay in particular during a long journey over continents when the weather was changing.

Keywords: Wet land, wasur national park, migrant bird, swamp forest.

\section{PENDAHULUAN}

Papua merupakan daerah kepulauan, bagian dari Negara Republik Indonesia dengan luas daratan mencapai \pm 160.000 mil $^{\mathbb{2}}$ yang kaya akan keanekaragaman hayati. Kawasan hutan papua berdasarkan Keputusan Menhutbun Nomor 891/KptsII/1999 seluas 42,224 juta Ha. Kawasan hutan tersebut dibagi dalam kelompok fungsi hutan yaitu fungsi Konservasi (cagar alam, suaka marga satwa) Fungsi lindung, (pelestarian alam, sistem penyangga kehidupan), fungsi produksi (produksi terbatas, produksi tetap, produksi yang dapat dikonversi) serta kawasan perairan (UU Nomor 5 Tahun 1990).

Pulau Papua dengan bentuk penampakan fisiografi yang indah sehingga dapat terbentuk lingkungan habitat dengan zona-zona yang sangat lengkap di Asia-Pasifik yang tersusun formasi mulai dari daerah pantai hingga pegunungan alpin. Kelestarian ekosistim hutan lahan basah berlangsung secara alami maupuan secara buatan.

Kawasan lahan basah Taman Nasional Wasur (TNW) dengan luas 413.810 ha,memiliki suatu kesatuan ekosistem dataran rendah yang konsisten antara tumbuh-tumbuhan dan komponen biotik di sekitarnya, menjadikan TNW sebagai salah satu kawasan konservasi yang terletak di wilayah timur indonesia dan terbentang di bagian selatan Pulau Papua (Yuliana dkk. 2012). Kawasan
TNW yang memiliki kerakteristik sebagai kawasan lahan basah yang sangat luas secara ekologis berada pada wilayah ekoregion transfly dan berbatasan langsung dengan suaka marga satwa tonda di Negara Papua New Guinea (PNG) yang merupakan daerah lahan basah yang sangat penting bagi burungburung air di Indonesia secara khusus burung yang berasal dari Australia dan Selandia Baru sehingga sangat memiliki arti penting bagi tempat persinggahan ribuan burung migrasi. Beberapa jenis burung migrasi diantaranya adalah Boha (Magpie geese), Ndarau (Cranes transfly), Ibis (Straw-necked), Glossy dan White, Paruh Sendok (Royal spoonbills) dan lain-lain (Winara 2015).

Dari berbagai literatur tentang keragaman hayati spesies burung di dunia menerangkan bahwa di Indonesia terdapat sekitar 1.598 spesies burung yang mana mewakili hampir $17 \%$ dari total spesies burung dunia. Burung-burung yang ada di Indonesia dan sebagian besar ditemukan di kawasan Timur Indonesia. Pantai selatan Papua, terutama TNW telah mencatat bahwa sekitar 403 species burung dengan 74 species diantaranya endemik Papua telah ada di TNW dan terdapat 114 species yang merupakan burung dengan status dilindungi termasuk burung migran (Winara 2015). Dengan demikian maka sudah menjadi perhatian pemerintah dalam pengembangan sistim pengelolaan yang baik guna kelestarian 
ekosistem kawasan TNW sebagai tempat persinggahan berbagai spesies burung dan juga mendukung kehidupan dan habitat satwa liar. Migrasi antara pulau dan benua merupakan suatu proses beradaptasi perilaku hidup pada lingkungan atau habitat yang baru oleh beberapa jenis satwa liar. Jenis satwa dapat beradaptasi dengan suatu habitat tergantung pada keadaan topografis, iklim dan waktu pada daerah tertentu (Alikondra 1990; Irawan 2004). Tujuan dari penelitian ini yakni untuk dapat memberikan gambaran tentang arti penting kawasan hutan lahan basah dan deskripsi pengelolaan kawasan lahan basah sebagai habitat burung migran.

\section{METODE PENELITIAN}

Penelitian ini dilaksanakan selama 4 bulan dari bulan mulai dari bulan Desember 2013 s/d April 2014 yang bertempat di Kabupaten Maokwari. Penelitian ini mengacu pada variabel utama yang dikaji yaitu dengan melihat karakteristik bentang lahan basah (wet land landscape) sebagai habitat burung migran dengan cakupan antara lain: kawasan yang memiliki ekosisten hutan, ekologi dan biologi kawasan yang beragam. Selain itu juga mengakaji pola dan sistem mengelolaan kawasan lahan basah TNW oleh stakeholder-stakeholder terkait dan upaya tindak lanjut pengelolaan kawasan TNW tersebut. Selain itu informasi terkait sejarah kawasan, keragaman hayati dan kemitraan serta nilai sosoal ekonimi dan budaya masyarakat juga menjadi komponen tambahan dalam penelitian ini.

Metode Pengumpulan Data

Data yang di kumpulkan dalam penelitian ini bersumber dari data sekunder berupa bahan tulisan dari berbagai referensi dan literature terpercaya melalui kajian akademis berkaitan dengan obyek penelitian seputar kawasan TNW.

\section{Analisis Data}

Data di perloleh di analisis secara deskristif dan selanjutnya data di tampilkan dalam bentuk tabel dan gambar.

\section{HASIL DAN PEMBAHASAN}

\section{Ekosistem Lahan Basah TNW}

Hasil Identifikasi yang di peroleh bahwa lahan basah yang berada di dalam kawasan TNW memiliki keunikan tersendiri dari tipe daratan lainnya di wilayah Papua dimana memiliki iklim dua musiman serta cuaca yang tidak menentu (fluktuasi yang tinggi). Kekhasan keanekaragaman ini dipengaruhi oleh tipe kawasan hutan, daerah keterisolasian spesies, daya segmentasi kawasan atau daya tarik lingkungan, sehingga dapat menciptakan suatu ekositem hutan yang unik. Kawasan lahan basah wasur merupakan daratan yang jenuh terhadap air baik air tawar dan air asin (rawa-rawa serta sungai-sungai).

Berdasarkan uraian tabel 1, terlihat distribusi karakteristik hutan dataran berair di seluruh kawasan TNW yang mana cukup tersebar merata hampir diseluruh kaasannya. Hal ini didukung oleh bentang lahan yang cenderung rata (flatted area) sehingga memungkinkan untuk terjadi genangan-genangan air baik dalam jumlah kecil maupun besar yang membetuk rawa permanen (Almin and Road 2001). 
Tabel 1. Ekosistem hutan dataran berair di sekitar kawasan TNW.

\begin{tabular}{|c|c|c|c|}
\hline No. & Tipe Ekositem & Sebaran Lokasi & Keterangan \\
\hline 1. & $\begin{array}{l}\text { Rawa berair } \\
\text { payau musiman }\end{array}$ & $\begin{array}{l}\text { Rawa Tahram, Rawa } \\
\text { Kitar-kitar hingga } \\
\text { daerah Waam dan } \\
\text { Samleber. }\end{array}$ & $\begin{array}{l}\text { Daerah tersebut terisolasi pada } \\
\text { saat musim banjir dan kembali } \\
\text { normal tawar pada saat } \\
\text { kemarau. }\end{array}$ \\
\hline 2. & $\begin{array}{l}\text { Rawa berair } \\
\text { tawar permanen }\end{array}$ & $\begin{array}{l}\text { Danau Rawa Biru, Ukra, } \\
\text { Maar dan Kankania. }\end{array}$ & $\begin{array}{l}\text { Keseluruhan wilayah terisikan air } \\
\text { tawar permanen. }\end{array}$ \\
\hline 3. & $\begin{array}{l}\text { Pesisir berair } \\
\text { tawar }\end{array}$ & $\begin{array}{l}\text { Mbo, Okilur, Rawa } \\
\text { Pilmul dan Rawa Badek. }\end{array}$ & Perisir yang berair tawar permanen. \\
\hline 4. & $\begin{array}{l}\text { Daratan berair } \\
\text { tawar }\end{array}$ & $\begin{array}{l}\text { Sepanjang jalan Trans } \\
\text { Irian. }\end{array}$ & $\begin{array}{l}\text { Pada bagian wilayah yang datar } \\
\text { tanah berair tawa. }\end{array}$ \\
\hline 5. & $\begin{array}{l}\text { Pesisir berair } \\
\text { payau - asin }\end{array}$ & $\begin{array}{l}\text { Sekitar pemukiman } \\
\text { sektor pantai kecuali } \\
\text { Kampung Kondo. }\end{array}$ & $\begin{array}{l}\text { Kawasan pesisir pantai yang secara } \\
\text { kontinyu mengalami pasang surut ait } \\
\text { laut daratan berair asin dan selobar. }\end{array}$ \\
\hline 6. & $\begin{array}{l}\text { Daratan berair } \\
\text { payau }\end{array}$ & $\begin{array}{l}\text { Kampung Wasur, Rawa } \\
\text { Ndalir dan Kampung } \\
\text { Sota. }\end{array}$ & $\begin{array}{l}\text { Daratan terisolasi masuknya air laut } \\
\text { menjadi selobar. }\end{array}$ \\
\hline
\end{tabular}

Sumber: Irawan 2004, Data Base Taman Nasional Wasur

Ekologi Lahan basah

Secara umum daerah wasur adalah dataran dengan jenis tanah aluvial dan jenis-jenis tanah lain yang merupakan jenis hasil dari proses pelapukan. Fenomena ini cenderung mengarah ke dataran berbukit hutan gambut pada wilayah-wilayah tertentu yang mana di dalamnya memiliki 7 tipe ekologi hutan pada lahan basah. Berikut deskripsi kawasan dan bentang ekologinya yang tersebar pada kawasan TNW.

Tabel 2. Tipe ekologi bentang daratan pada kawasan TNW.

\begin{tabular}{lll}
\hline No. & \multicolumn{1}{c}{ Tipe Ekologi } & \multicolumn{1}{c}{ Sebaran Lokasi } \\
\hline 1. & Daratan teras pleistosen & Desa Yanggandur dan Sota. \\
2. & Daratan lebak & Desa Ukra, Kankania, Mblatar dan Wasur. \\
3. & Daratan sungai & Kampung Bokrum, Desa Tambat dan Sota. \\
4. & Daratan rawa bakau & Desa Kondo dan sekitarnya. \\
5. & Daratan rawa air tawar & Desa Rawa Biru dan sekitarnya. \\
6. & Daratan pantai & Kuler, Onggaya, Tomer, desa Tomerau dan \\
& & sekitarnya yang memanjang sampai ke Papua \\
7. & Bekas dataran pantai & New Guenia. \\
& & Sekitar Waam dan Samleber hingga sungai \\
\hline
\end{tabular}

Sumber: Irawan 2004, Data base Taman Nasional Wasur 
Berdasarkan karakteristik tipe ekologi pada Tabel 2 di atas terindikasi bahwa bahwa TNW memiliki tipe ekologi dan bentang daratan dengan jenis tanah yang membetuk dan menyusun tipe hutan dataran rendah di selatan Papua. Secara umum semua semua tipe ekologi tersebut berada pada bentang lahan yang relatif datar sehingga tidak dimungkinkan untuk terlihat berbeda secara signifikan antara satu tipe ekologi dengan tipe ekologi lainnya, terutama komposisi vegetasi dan tumbuhan bawahnya (Threlfall et al. 2016). Namun dari sisi keragaman jenis terutama jenis vegetasi dataran rendah cukup tinggi karena daya dukung kawasan dan karakteritsik komponen biotik yang nmasih baik sehingga memungkinan perkembang biakan flora dan fauna yang cukup cepat terjadi.

\section{Biologi Lahan basah}

Kawasan hutan di TNW memiliki keragaman hayati yang cukup tinggi yang selanjutnya terbagi ke dalam 4 zona yang di dalamnya terdapat 10 formasi hutan yang beragam yang disajikan pada tabel 3 .

Tabel 3. Beberapa tipe formasi hutan dataran rendah di sekitar kawasan TNW.

\begin{tabular}{|c|c|c|c|}
\hline No. & Formasi Hutan & $\begin{array}{l}\text { Luas } \\
(\mathrm{Ha})\end{array}$ & Jenis Vegetasi \\
\hline 1. & $\begin{array}{l}\text { Dominan } \\
\text { Melaleuca }\end{array}$ & 33.535 & $\begin{array}{l}\text { Melaleuca spp., Lophostemon lactifluus, Xanthostemon sp., } \\
\text { Acacia leptocarpa, Salsar, Asteromyrtus symphiocarpa, } \\
\text { Eucalypthus spp., Alstonia actinopilla, dll. }\end{array}$ \\
\hline 2. & $\begin{array}{l}\text { Co-Dominan } \\
\text { Melaleuca } \\
\text { Eucalypthus }\end{array}$ & 33.874 & $\begin{array}{l}\text { Melaleuca spp., Eucalypthus sp., Asteromyrtus } \\
\text { symphiocarpa, Salsar, Xanthostemon sp., Acacia } \\
\text { leptocarpa, Alstonia actinopilla, Dilenia alata, dll. }\end{array}$ \\
\hline 3. & Hutan Jarang & 34.559 & $\begin{array}{l}\text { Lophostemon lactifluus, Melaleuca sp., Dilenia alata, } \\
\text { Eucalypthus sp., Asteromyrtus symphiocarpa, Acacia } \\
\text { leptocarpa, Xanthostemon sp., yang di bawahnya } \\
\text { ditumbuhi berbagai semak. }\end{array}$ \\
\hline 4. & Hutan Pantai & 4.748 & $\begin{array}{l}\text { Alstonia actinopilla, Naudena-Barringtonia sp., } \\
\text { Lophostemon lactifluus, Cocos nucifera dan berbagai jenis } \\
\text { palem. }\end{array}$ \\
\hline 5. & Hutan Musim & - & $\begin{array}{l}\text { Eucalypthus sp., Acacia mangium, Dilenia alata, Alstonia } \\
\text { actinopilla, Salsar, dll.), Bamboo sp., Graminae spp. }\end{array}$ \\
\hline 6. & $\begin{array}{l}\text { Hutan Riparian } \\
\text { (Pinggir Sungai) }\end{array}$ & 43.372 & $\begin{array}{l}\text { Eucalypthus sp., Acacia mangium, Dilenia alata, Alstonia } \\
\text { actinopilla, Salsar,Bamboo sp., Graminae sp. }\end{array}$ \\
\hline 7. & Hutan Bakau & 51.752 & $\begin{array}{l}\text { Sonneratia sp., Avicenia sp., Rhizophora sp., Bruguiera sp., } \\
\text { Nypa frcticans dan palem. }\end{array}$ \\
\hline 8. & Hutan Savana & 169.809 & $\begin{array}{l}\text { Lophostemon lactifluus, Banksia dentata, Asteromyrtus } \\
\text { symphiocarpa, Eucalypthus sp., Melaleuca sp. }\end{array}$ \\
\hline 9. & Padang Rumput & 8.911 & Graminae sp. dan Pandannus sp. \\
\hline 10. & $\begin{array}{l}\text { Padang Rumput } \\
\text { Rawa }\end{array}$ & 13.250 & $\begin{array}{l}\text { Pandannus sp., Phragmites karka, Hanguana sp., anggrek } \\
\text { dan teratai. }\end{array}$ \\
\hline
\end{tabular}

Sumber: Widya 2009, Keanekaragaman Hayati Taman Nasional Wasur 
Secara tipologi kawasan, terlihat bahwa formasi hutan dan terbentuknya struktur komunitas vegetasi cenderung mengikuti kontur dan bentang lahan kawasan di sekitar TNW. Jenis kelompok vegetasi yang dominan berasar dari jenis Melaleuca yang tersebar hampir pada seluruh kawasan dikarenakan daya dukung kondisi tanah dan karakteristik ekosistem yang sesuai serta menunjang pertumbuhan dari jenis Melaleuca. Namun secara luasan, tipe hutan savanna masih mendominasi dengan luasan mencapai 169.911 dibandngkan tipe hutan dan vegetasi lainnya. Dominasi hutan savana tidak lain didukung oleh kondisi tanah dan iklim yang mana cenderung lebih kering dengan persentasi kehadiran hujan yang kurang sepanjang tahunnya (Baudena et al. 2015).

\section{Pengelolaan Kawasan Lahan Basah}

Pengelolaan kawasan lahan basah TNW dari luas yang berjumlah 413.810 ha dilakukan dengan sistem zonasi berdasarkan SK. Dirjen PKA No:15/Kpts/DJ-V/2001, sebagai kawasan yang mempunyai fungsi sistem penyangga kehidupan. Untuk menjaga dan melestarikan kawasan teresebut, maka kawasan lahan basah TNW di bagi ke dalam tiga seksi pengelolaan kawasan Taman Nasional yaitu:

1. Pengelolaan Taman Nasional Wasur Wilayah I Agrindo dengan luas 54.420 ha.

2. Pengelolaan Taman Nasional Wasur Wilayah II Ndalir dengan luas 170.600 ha.

3. Pengelolaan Taman Nasional Wasur Wilayah III Wasur dengan luas 188 ha.

Kawasan lahan basah TNW dikelola dalam 3 (tiga) wilayah berlandaskan prinsip keleslestarian alam sesuai peruntukannya dengan membentuk zonasi-zonasi:

Tabel 4. Pembagian zona pengelolaan kawasan TNW.

\begin{tabular}{|c|c|c|c|c|c|c|}
\hline \multirow[t]{2}{*}{ No. } & \multirow[t]{2}{*}{ Zonasi } & \multirow[t]{2}{*}{$\begin{array}{l}\text { Luas/ } \\
\mathrm{Ha}\end{array}$} & \multicolumn{2}{|c|}{$\begin{array}{c}\text { Luas Terbagi } \\
\text { dua } \pm / \mathrm{km}\end{array}$} & \multirow{2}{*}{$\begin{array}{c}\text { P.Kel } \\
\pm \\
/ \mathrm{m}^{2}\end{array}$} & \multirow[t]{2}{*}{ Keterangan } \\
\hline & & & $\mathrm{U}$ & $\mathrm{S}$ & & \\
\hline 1. & Inti & $\begin{array}{c}127.59 \\
0\end{array}$ & 82 & 184 & 266 & Sebagian wilayah tidak terhitung \\
\hline 2. & Rimba & $\begin{array}{c}211.32 \\
0\end{array}$ & 229,2 & 316,8 & 546 & Sebagian wilayah tidak terhitung \\
\hline 3. & Pemanfaatan & 56.100 & - & - & 380 & Wilayah tidak menentu \\
\hline 4. & Pemukiman & 18.800 & - & - & 247,2 & $\begin{array}{l}\text { Terdapat beberapa desa dan memiliki } \\
\text { lausan tertentu: Desa Kondo } \pm 20 \mathrm{~km} \text {, } \\
\text { Tomerau } \pm 18 \mathrm{~km} \text {, Wasur } \pm 13,4 \mathrm{~km} \text {, } \\
\text { Rawa Biru (Yereu) } \pm 20,4 \mathrm{~km} \text {, } \\
\text { Yanggandur } \pm 15 \mathrm{~km} \text {, Sota } \pm 18 \mathrm{~km} \text {, } \\
\text { Bokrum } \pm 25,8 \mathrm{~km} \text {, Tambat } \pm 23,8 \\
\text { km dan Soa } \pm 19,2 \mathrm{~km} .\end{array}$ \\
\hline
\end{tabular}

Sumber: Irawan 2004, Data Base Taman Nasional Wasur

Pada Tabel 4 dideskripsikan tata kelola kawasan dengan pembagian zonasi antrara lain: zona inti, rimba, pemanfaatan dan zona pemukiman yang 
didasarkan pada ketentuan daerah zonasi berdasarkan SK. Dirjen PKA No:15/Kpts/DJ-V/2001.

\section{Sistim pengawasan Pemerintah Terhadap Kawasan TNW}

\begin{tabular}{llr}
\multicolumn{1}{c}{ Pemerintah } & melakukan & kegiatan \\
perlindungan, & pengawasan & dan \\
pengamanan & terhadap & kawasan
\end{tabular}
konservasi termasuk TNW yang menjadi ikon konservasi di selatan Papua. Namun sering kali bertentangan dengan pola pemanfaatan dan budaya masyarakan lokal yang mana secara turun temurun menggantungkan hidupnya dari hutan sekitarnya termasuk kawasan TNW. Melalui solusi keterlibatan masyarakat kampung di sekitar kawasan TNW memberikan efek positif terhadap upaya pengelolaan kawasan dan konservasi flora dan fauna yang ada di dalamnya. Pemerintah mengikutsertakan beberapa masyatakat dalam pengelolaan dengan membentuk kader konservasi yamg mana kader-kader tersebut merupakan pemilik hak ulayat sehingga menjadi lebih efektif dan berpengaruh lebih baik. Mengupayakan konservasi yang diintegrasikan ke dalam budaya dan adat istiadat masyarakat lokal terlihat cukup efektif. Secara lebih luas, pengelolaan kawasan dengan desain pos monitoring menjadi salah satu altermatif yang efektif guna menjaga nilai keragaman dan biodiversitas kawasan TNW.

Sejauh ini pihak pengelola UPT Kehutanan Balai TNW bersama SPKP serta di dukung oleh lembaga-lembaga pemerintah, swasta serta perguruan tinggi telah banyak melakukan penyadaran kepada masyarakat dalam pemanfaatan kawasan yang lebih lestari dan lebih fokus kepada keberadaan kawasan hutan yang menjadi fungsi utama sebagai kawasan pelestarian alam dan sistem penyangga hidupan (Widya 2009).

\section{Program Konservasi Kawasan Lahan Basah Wasur}

Berdasarkan hasil identifikasi bahwa upaya-upaya yang telah dilakukan oleh pihak Balai TNW bersama masyarakat desa hutan serta mitra konservasi dan pelajar telah banyak menginisiasi beberapa kegiatan penting pada kawasan lahan basah guna menjaga keberadaannya yang antara lain:

1. Secara langsung melakukan inventarisasi dan identifikasi potensi kawasan yang menjadi sasaran aktifitas bagi satwa liar, terutama burung migran terutama pada beberapa tipe ekologi penting seperti rawa, pantai, hutan monson dan hutan jarang dengan tegakan Melaleuca.

2. Memperbaiki atau memulihkan kembali habitat yang mengalami kerusakan baik tumbuhan, satwa atau ekosistem di setiap kawasan konservasi. Pada prinsipnya dapat dilakukan pembinaan habitat, namun di dalam pelaksanaannya harus tetap memperhatikan prinsip-prinsip dasar konservasi.

3. Untuk menjaga kualitas dan kuantitas jenis tumbuhan dan satwa agar tetap berada dalam keadaan seimbang di setiap kawasan konservasi pada prinsipnya dapat dilakukan pembinaan populasi.

4. Melakukan kegiatan rehabilitasi pada setiap kawasan konservasi dengan memperhatikan segi teknis dan ilmiah. Rehabilitasi lahan dapat dilakukan atas dasar adanya kebutuhan untuk memperbaiki kondisi kawasan yang potensinya rusak atau peruntukannya menurun 
melalui pemilihan jenis tumbuhan, pohon yang baik.

5. Melakukan kegiatan perlindungan, pengawasan dan pengamanan terhadap satwa liar dan tumbuhan serta kawasan yang menjadi habitat burung migran. Pengawasan terhadap setiap flora dan fauna serta kawasan tersebut agar tidak diganggu atau terjadi ancaman kerusakan (kebakaran, perburuan dll). Melakukan pengamanan terhadap unsur-unsur yang dengan sengaja atau tidak sengaja melakukan tindakan melanggar aturan yang telah ditetapkan pemerintah dan aturan adat setempat.

6. Meningkatkan pemahaman masyarakat lokal dengan melakukan kegiatan pendekatan dan penyuluhan secara kontinyu akan pentingnya keberadaan burung-burung migran di pantai selatan Papua yaitu dengan kegiatan penyuluhan oleh petugas kehutanan secara kelompok dan individu.

7. Pembinaan daerah penyangga dititik beratkan pada upaya peningkatan hubungan yang harmonis antara masyarakat dan kawasan hutan yang sedemikian rupa sehingga dapat di pahami bahwa dengan adanya kawasan konservasi, masyarakat dapat merasakan manfaatnya secara terus menerus. Adapun juga kegiatankegiatan dengan melibatkan beberapa masyarakat seperti kader konservasi.

\section{Peranan Lahan Basah Dari Segi Ekologi}

Secara umum terdapat beberapa manfaat penting secara ekologis terhadap peran lahan bbahsa bagi keberlangsungan proses kehidupan di alam dan keseimbangan ekosistem hutan yang antara lain: Pertama, sebagai kawasan penampung unsur hara. Ekosistem hutan lahan basah ini dapat menahan dan mendaur ulang unsur hara dan sebagai derah pengendapan sedimen dari hulu. Kedua, sebagai pengendali pencemaran yang mana kombinasi badan air di kawasan lahan basah dapat mengurangi konsentrasi bahan tercemar dan menetralisir komponen toksik yang berbahaya bagi kehidupan komponen biotik lainnya. Ketiga, menstabilkan iklim mikro, dimana secara keseluruhan kondisi hidrologi dan daur materi pada lahan basah dapat menstabilkan iklim mikro, terutama curah hujan dan suhu. Keempat, ekosistem hutan lahan basah juga dapat berfungsi sebagai pengendali iklim global yang sangat besar dan sasaran utama berperan pada hutan rawa gambut. Vegetasi hutan gambut dapat membantu proses penyerapan $\mathrm{CO}_{2}$ dalam jumlah besar dari udara melalui proses fotosintesis dan sebagai penyimpan karbon sehingga dapat mencegah pemanasan global.

\section{Burung Migrasi}

Hasil identifikasi mengindikasikan bahwa migrasi burung terjadi setiap tahun yang mengembara dari tempat berbiakannya di daerah tundra Arktik menuju ke selatan untuk menghindari musim dingin pada bulan Mei dan Juni hingga November tiap tahunnya. Guna menghindari ancaman yang tingg maka burung-burung pantai kebanyakan beristirahat dan mencari makan di wilayah Asia, sementara yang lainnya melakukan perjalanan menuju Australia dan Selandia Baru. Pada November/Desember ketika musim panas tiba di belahan bumi utara, maka burung- 
burung tersebut akan kembali ke utara untuk berkembang biak (Widya 2013).

\section{DAFTAR PUSTAKA}

Alikodra HS. 1990. Pengelolaan satwa liar. Jilid I. Pusat Antar Universitas Ilmu Hayat,Institut Pertanian Bogor //www.satwaliar.blogspot.com

Almin NA and Road SB. 2001. Inundation tolerances riparian willows and cotoonwoods. Jounral of the American Water Resources Association, Vol 37 (6): 1709-1720.

Baudena M, Dekker SC, van Bodegom PM, Cuesta B, Higgins SI, Lehsten V, Reick CH, Rietkerk M, Scheiter S, Yin Z, Zavala MA and Brovkin V. 2015. Forests, savannas, and grasslands: briding the knowledge gap between ecology and dynamics global vegetation models. Biogeosciences, Vol 12: 1833-1848.

Irawan N. 2004. Pembuatan data base di Taman Nasional Wasur Merauke.

Threlfall CG, Assolo A, Hahs AK, Williams NSG, Wilson $\mathrm{L}$ and Livesley SJ. 2016. Variation in vegetation structure and composition across urban green space types. Front. Ecol.

Evol, https://doi.org/10.3389/fevo.2016.000 $\underline{66}$.

Undang-Undang Nomor 5. 1990. Konservasi sumber daya alam hayati dan ekosistemnya. Menteri/Sekretaris Negara Republik Indonesia.

Widya YA. BTN Wasur, 05-02-2009 Hari Lahan Basah Sedunia dirayakan di Taman Nasional WasurMerauke. www.btnwasur.blogspot.com

WidyaYA. 2011

Keanekaragamanhayatiwasur /http.www.btwasur,blogspot. com

Widya YA. 2009. Pembentukan Sentra Penyuluhan Kehutanan Pedesaan (SPKP) Kampung Wasur, Taman Nasional

WasurMerauke.www.btnwasur.blogs pot.com.

Winara A. 2015. Keragaman jenis burung air di Taman Nasional Wasur, Merauke. Jurnal Hutan Tropis, Vol 4 (1): 85-92.

Yuliana S, Lekitoo $\mathrm{K}$ dan Tambing Y. 2012. Kajian invasi tumbuhan pada lahan basah Taman Nasional Wasur, Merauke. Makalah disampaikan pada Seminar Hasil-Hasil Penelitian BPK Manado - BPK Manokwari di Manado 23-24 Oktober 2012. 